\title{
USING QUALITATIVE METHODS TO HOLISTICALLY ASSESS AND EVALUATE CEAB'S LIFELONG LEARNING ATTRIBUTE IN SCHULICH'S SCHOOL OF ENGINEERING AT THE UNIVERSITY OF CALGARY
}

\author{
Lisa Stowe and Rachel Huh \\ University of Calgary \\ lstowe@ucalgary.ca, rachel.huh@ucalgary.ca
}

\begin{abstract}
This paper will show the process of how one research project measured and assessed lifelong learning in University of Calgary's Schulich School of Engineering (SSE). The researchers used an extensive and holistic methodology to assess and detail how this program fosters lifelong learning in its undergraduate students fulfilling the CEAB's accreditation attribute for lifelong learning. This evaluative process can be replicated in other engineering programs to measure lifelong learning amongst undergraduates.
\end{abstract}

Keywords: Lifelong learning attribute, CEAB accreditation, Holistic and qualitative methodology

\section{INTRODUCTION}

Maintaining standards and ensuring program quality in Canadian post-secondary engineering programs is the role of the Canadian Engineering Accreditation Board (CEAB). The CEAB lists 12 graduate attributes that help accredited programs ensure their graduates are prepared and qualified to become professional engineers. Universities with accredited engineering programs are required to show how their students acquire these attributes through their years in the program. One of those graduate attributes is lifelong learning. The CEAB defines lifelong learning as, "an ability to identify and address their own educational needs in a changing world in ways sufficient to maintain their competence and allow them to contribute to the advancement of knowledge" [3]. The problem with lifelong learning is the complexity of how students become lifelong learners and it can be sometimes difficult to assess this attribute using quantitative measurements or even observational methods. A more qualitative and holistic exploration of a program can more deeply assess whether or not the program is fostering lifelong learning and achieving the CEAB's lifelong learning attribute.

This paper will outline an evaluative methodology ${ }^{1}$ to measure lifelong learning to show how other engineering schools can use this evaluation process to help understand if their own programs are fostering lifelong learning. As well, we will describe the various qualitative methods used in this project to show how this approach can help researchers assess other engineering programs' ability to foster lifelong learning.

\section{BACKGROUND}

Our qualitative research project assisted in helping the University of Calgary's Schulich School of Engineering (SSE) assess their lifelong learning attribute. We started with an extensive and conceptual definition of lifelong learning. We then employed a variety of qualitative methods that provided a thorough and holistic overview of this program's ability to help students become lifelong learners.

\subsection{Definition of lifelong learning}

Before outlining the qualitative methods used to holistically explore SSE's lifelong learning attribute, we need to establish what we mean by lifelong learning. Defining lifelong learning is complicated. Our perspective emphasizes that lifelong learning is more related to learner centered experiences that can occur regardless of space, place, or program. With this in mind, educators then become responsible for validating the learning that takes place beyond the confines of a formal curriculum and locate lifelong learning within the learner themselves [1], [5], [6], [7], [12]. What results from this approach to lifelong learning is that a lifelong learner requires initiative (self-motivation) [2,] and discipline on the student's part and that the learner must assume responsibility for their learning [10].

An institution can assist with this by intentionally designing courses, assignments and assessment that foster a learner's self-directed initiative. Institutions can encourage this self-directed initiative by:

- Expecting students to effectively manage their education: students plan and specify educational goals

\footnotetext{
${ }^{1}$ Results and sections in this paper were originally compiled in an assessment report commissioned and submitted to SSE.

CEEA18; Paper 017

University of British Columbia; June 3-6, 2018
} 
- Employing active methods of learning: students are more engaged with a variety of teaching methods

- Engaging students in design problems: students are engaged in open-ended activities that require integration across disciplines as well as trial and error

- Engaging students in research: students are active and engaged by discovering new knowledge [10]. As well, students who engage with self-assessment or reflection assignments will also be more inclined to see how learning can take place throughout their lives in various contexts and not just as formal upgrading or vocationalization [4], [7], [12]. These pedagogical strategies will help foster a lifelong learning culture that transcends courses or programs and will mean lifelong learning for students becomes life-wide rather than course or program based [8].

\subsection{Lifelong learning is learner centered}

Our conceptual definition is then focused on lifelong learning as related to learner centered experiences that can occur regardless of space, place, or program. To help assess whether a program fosters the environment to encourage students to become lifelong learners we outline Knapper and Cropley's five lifelong learning characteristics [9] that, if present in a program's curriculum, can help students learn to learn. Students should be encouraged to:

- set goals,

- apply appropriate knowledge and skills,

- engage in self-direction and self-evaluation,

- locate information beyond the classroom and,

- $\quad$ adapt to new learning situations.

It is our belief that if engineering programs successfully encourage all five characteristics, then the chances they are preparing their students for lifelong learning is very high.

\section{METHODS}

The original assessment project was a qualitative research project that focused on a holistic approach to assessing on engineering program. This holistic approach took a wide view of the SSE's overall curriculum and course delivery to understand the program lifelong objectives from multiple angles and perspectives.

To begin this process, we started with an interpretive understanding of the CEAB's definition of lifelong learning, combined with a review of the SSE's program descriptions in the academic calendar as well as the faculty website. This material along with a review of the scholarly lifelong learning literature were used to develop two foundational research questions that guided this project.

1.To what extent are SSE's courses and programs fostering lifelong learning in students?

CEEA18; Paper 017

University of British Columbia; June 3 - 6, 2018
2.How does SSE fulfill the Engineering Canada's definition of lifelong learning?

Once the questions were developed, we then engaged in a variety of qualitative methods to understand how the SSE's curriculum and programs foster lifelong learning. The holistic and multi-pronged approach focused on gaining a depth of knowledge about lifelong learning in SSE as well as a breadth of understanding as we reviewed multiple courses and programs.

\subsection{Research Design}

Our research design focused on exploring SSE's lifelong learning attribute from a variety of perspectives. A combination of inductive and deductive coding was completed to gain an overview of the program itself. This Thematic Coding Analysis (TCA) included content analysis and thematic coding of course binders and website program descriptions. Concurrently, we conducted one to one semi-structured faculty interviews, which were then thematically coded and compared to the thematic coding for the course binders. To increase multiple perspectives on how effective SSE's program was in fostering the lifelong learning attribute, we developed and administered online surveys to all of the stakeholders in the SSE. These stakeholders included faculty, students and alumni and the online surveys asked them a variety of qualitative and quantitative style questions related to the teaching and learning they experienced in SEE's programs. Questions focused on surveying these participants in the five characteristics outlined in Knapper and Cropley [9]. We were confident that such a thorough research design provided a holistic examination of how SSE fostered lifelong learning. Our hope is that such a research assessment and evaluative process can be replicated at other university's engineering programs to help explore their program's lifelong learning attribute.

\section{RESULTS AND DISCUSSION}

During this research project we were faced with a mountain of data that at the time of analysis was overwhelming and unwieldy - a characteristic not uncommon in qualitative research. We were also pleasantly surprised at the level of depth and breadth of experience that the interviews and surveys gave us [11]. To help organize the data into manageable interpretive sections we coded all of the collected data using Knapper and Cropley's five characteristics as the basis for our thematic coding. Those five characteristics also organize this results and discussion section for this paper as it did for the report.

\subsection{Goal setting}

Self-motivation is an essential element for lifelong learning and a curriculum that encourages students to set 
goals fosters learning throughout life. Goal setting helps students become self-motivated. An instructor's intentional use of scaffolding is one evidential way to see goal setting in the curriculum [11]. Scaffolding of assignments is a way to structure course material and content in a way that helps students establish goals for their progression through a specific course and through courses at various levels of their program. By helping students incorporate revisions and guided reflection on answers and solutions throughout the course, students are also learning how to set goals and execute those goals.

As we coded SSE's curriculum by way of course outlines and assignment guidelines there was evidence of scaffolding in most courses with those at the higher level, especially design and independent study courses exhibiting more use of scaffolding than those courses at the lower levels [11]. This makes sense as most students will be better equipped to use material presented in former classes as they progress through the program. What impressed us the most and showed that SSE helped students set goals, was the fact that instructors were intentionally designing these higher-level courses to take advantage of the pedagogic notion of scaffolding.

Faculty interviews confirmed this intentionality and revealed that explicit expectation and goal setting was common practice amongst faculty. While the explicit use of the term 'lifelong learning' was rare, faculty agreed that facets of lifelong learning such as skill development, independent research, self-appraisal, and an ability to learn outside of formal classes were learning outcomes they communicated and expected from their students.

Students survey participants also strongly confirmed that SSE was successful at establishing the characteristic of goal setting. $70.73 \%$ of student respondents felt strongly that they set flexible and realistic learning goals while $64.38 \%$ of students agreed or strongly agreed that they often set learning goals that they revisited and adjusted as they learned, supporting the curriculum's evidence of scaffolding as a pedagogical tool to help students with this attribute of lifelong learning [11]. 79.95\% of students also suggested that they shaped their approach to learning according to their learning goals, reinforcing the intentional use of goal setting by students to progress through their program.

These three different data sets all confirm that SSE is highly successful at fostering the skill of goal setting which in turn is an important characteristic for students to become lifelong learners.

\subsection{Application of knowledge and skills}

The second lifelong learning characteristic that helps determine if a student is becoming a lifelong learner is application of knowledge and skills. Students who can take knowledge and skills from one context and apply it to a different context will be more inclined to learn throughout life. Our coding of the course binders and curriculum delivery methods with this characteristic in mind showed that the application of knowledge and skills was quite high in SSE. Course objectives emphasized skills acquisition, and explicitly stated that students will learn how to apply knowledge and skills. Faculty intentionally connected the skills an engineering student acquires with the professional skill set needed for the profession through clear expectations listed in course outlines and assignment guidelines. These skills included:

- An understanding of their role as an engineer with the potential for positive or negative impact in the world

- An ability to critically examine professional work

- A refinement of communication, teamwork, and project management skills as well as an appreciation for how knowledge can be applied beyond the theoretical

Course delivery methods also encouraged application of knowledge and skills. Case study, community-based learning and problem-based learning activities in class encouraged students to take previous knowledge and apply it to other situations. Exams included open book and written exam style questions which presumed a student will incorporate previous knowledge in an assessment situation.

The data set that revealed the most strongly that students were learning how to apply knowledge and skills to different contexts was the student surveys [11]. When surveyed about how SSE encouraged an application of knowledge and skills, students responded very strongly at $85.04 \%$ that skills learned in one course helped them with skill acquisition in another course. Students also responded quite high at almost $70 \%$ that they could see how their knowledge and skills learned in school could be utilized in contexts beyond school. There appears to be a strong positive response from students that they were being taught how to apply knowledge and skills within course between different assignments as well as between courses throughout their program [11].

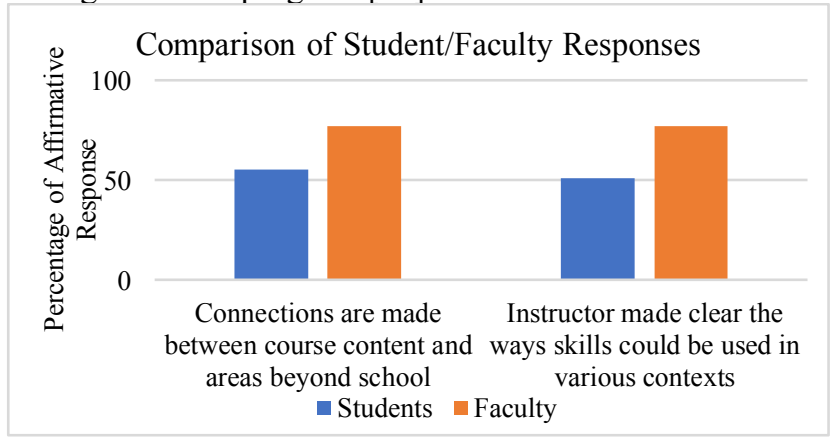

Figure 1. Misperception between faculty and students in the area of application of knowledge and skills.

CEEA18; Paper 017

University of British Columbia; June 3-6, 2018 
What was interesting to us as we interpreted this category was the disconnect between how students viewed this area and how faculty viewed it. As Fig. 1 shows students were not strongly convinced that their instructors intentionally instructed them on how apply knowledge and skills. This student perception of not explicitly hearing about the transfer of skills and knowledge might be connected to SSE faculty members' confusion about the means of assessment and lack of intentionality about designing assignments or course learning objectives that explicitly state this characteristic. The lack of inentionality in course outlines and assignment guidelines as to how learning outcomes related to this particlaur attribute was a common observation as we worked our way through the interpretive part of this project.

Another interesting data point for this characteristic came from the alumni survey, specifically how alumni ranked the value of classroom activities in preparing them for Engineering careers. Survey results showed that certain classroom activities are more highly valued than others when it comes to preparing Engineering graduates to learn throughout life [11]. Figure 2 shows on a scale of 1-7 (with 1 being the lowest order of importance to 7 being the highest order of importance) how alumni ranked various class activities that are thought to help students learn in different contexts. It is clear that alumni consider active learning techniques such as problem-based learning and project design to be the most valued form of assignments that help students transfer and apply knowledge and skills to new contexts.

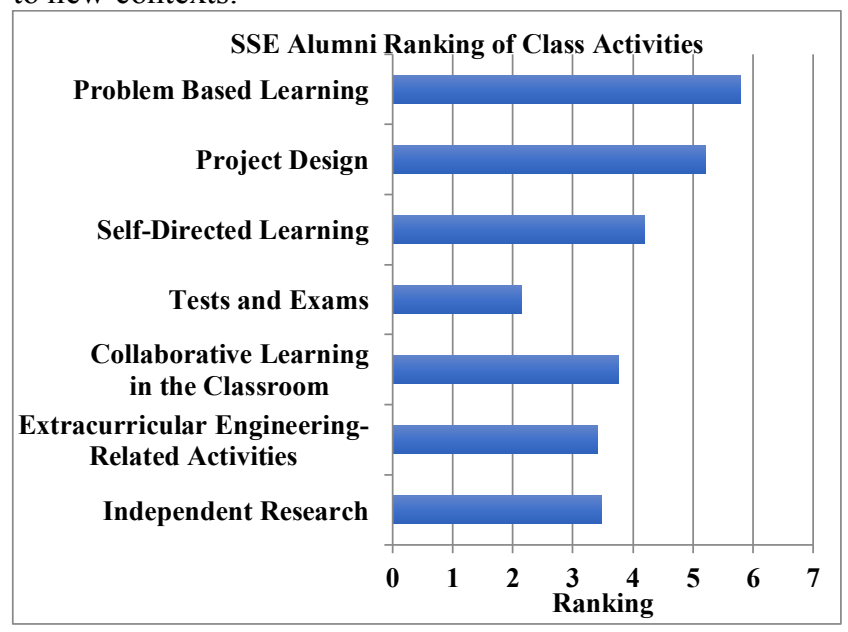

Figure 2: SSE Alumni ranking of classroom activities that help transition learning to different contexts

Through analysis of all these different data sets, SSE was again highly successful at fostering a specific characteristic that helps its students develop as lifelong learners, despite the disconnect between how students saw themselves acquiring those skills and how faculty saw themselves as promoting those skills.

CEEA18; Paper 017

University of British Columbia; June 3 - 6, 2018

\subsection{Self-direction and evaluation}

Part of the CEAB's definition of lifelong learning implies that engineering professionals need to address and take responsibility for their learning throughout life. The characteristic that most helps with this is self-direction and evaluation. Based on our conceptual definition of lifelong learning we also believe that students must be taught how to take personal responsibility of for their own learning in order to become successful lifelong learners. It was rewarding to see that SSE's course material also echoed this characteristic.

The coding of the course binders showed that some SSE courses are intentionally fostering self-direction and evaluation. Some of the more obvious examples of this are in the independent research/design courses where students are responsible for their own learning and self -direction. Other courses have elements, mostly assignment options, that might not be directly associated with self-direction and evaluation but do foster these characteristics. Various assignments like reflective thought (either through direct reflective style questions in class or the assigning of more structured reflective essays as assessment), open ended lab assignments that encourage students to take their own direction, peer assessment, and giving students choice on the direction of their design projects all ask students to become responsible for their own learning [11].

Despite the clear indication that SSE was fostering selfdirection and evaluation, the perceptions amongst faculty and students as to who was responsible for this was mixed. This again reinforced the idea of a large misperception between students and faculty similar to the one found in application of skills and knowledge area. Students were convinced that they were taking personal responsibility for their learning. Almost $90 \%$ of students surveyed responded strongly or very strongly that it was their responsibility to make sense of what they learned in school [11]. When interviewed, the SSE faculty all agreed that students are expected to be self-directed learners, especially by the time they are doing senior capstone design courses. However, it was apparent in the interviews that some faculty had little knowledge on how to encourage self-direction and evaluation. Some SSE faculty felt strongly that they did encourage self-direction and evaluation and some encouraged this intrinsic motivation formally with grades, while others saw more informal encouragement, such as creative course assignments and activities as a way to guide students towards this characteristic. The lack of explicitly stating this objective, either in course outlines, learning objectives or classroom discussion might be one reason why there is a misperception from students that they are not being encouraged to self-direct and self-evaluate.

This idea that students come to classes with an ingrained ability to reflect is seen in the faculty survey numbers. Faculty surveys showed a lack of intentional student reflection in assignments and class discussion. $37.50 \%$ of 
faculty agreed or strongly agreed that they encouraged selfevaluation, which is higher than student perception of this element but still not high. Only $31.25 \%$ of faculty surveyed said they assigned formal reflection style assignments or asked focused reflective questions in class. The strongest area where faculty believe they are asking students to selfevaluate in in formal written feedback on assignments. $68.75 \%$ of instructors agreed or strongly agreed that they provided detailed feedback on how students could improve their work.

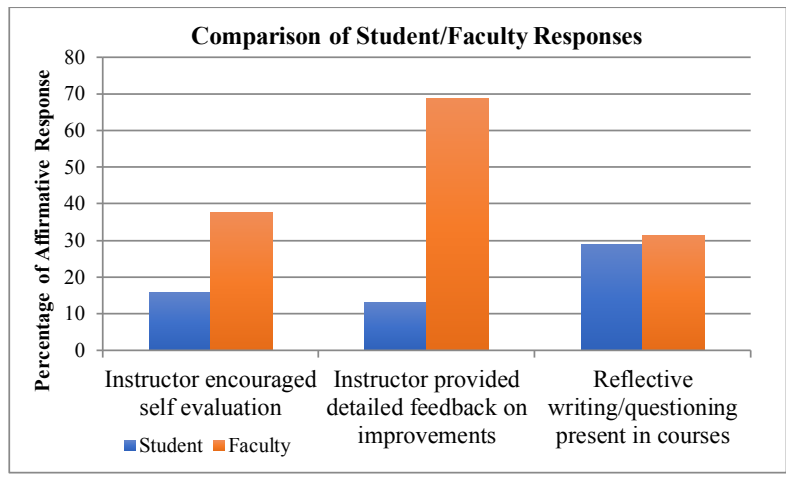

Figure 3: Faculty/Student responses to self-evaluation techniques in SSE curriculum

However, student responses did not support what the instructors were suggesting in their surveys and interviews. Figure 3 shows the level of misperception between students and faculty in the area of self-evaluation. Despite the opportunities students have for self-direction and selfevaluation in these courses, many who were surveyed suggested that overall in their program they were not given much encouragement to self-evaluate or to self-assess. Only $15.79 \%$ of respondents agreed that their instructor encouraged self-evaluation while only $13.16 \%$ agreed that their instructor provided detailed feedback on where they needed to improve. $28.94 \%$ agreed or strongly agreed to the statement, "I wrote at least one or two reflective pieces during my program or in my completed courses thus far" and only $43 \%$ said that their homework assignments and exams help them understand themselves as a learner. SSE students are well aware that they have to take responsibility for their own learning and to a certain degree some SSE courses do encourage students to self-evaluate and be selfdirected.

We were pleased to see that alumni surveys do support this perception amongst current SSE students that they do learn how to take personal responsibility for their own learning. Alumni surveys indicated high levels of confidence in self-direction. $87.5 \%$ were comfortable with working on their own with very little direction, while $93.75 \%$ felt confident in taking initiative to problem solve in their work and personal life.

CEEA18; Paper 017

University of British Columbia; June 3-6, 2018
Again, the various data sets do indicate that SSE students are learning the characteristic of self-direction and evaluation but there are misperceptions between faculty perceptions of how they are teaching this attribute and how students are learning this attribute.

\subsection{Locating information}

Locating information is an essential characteristic for fostering lifelong learning because it implies that students can confidently find the information they need to complete a project or assignment on their own [11]. This characteristic also helps foster the notion of self-directed learning, an important factor when helping students see how they learn throughout life.

Students surveyed expressed a high level of confidence when it came to locating information beyond the formal class content. Figure 4 clearly shows students acquire knowledge from a wide variety of sources. $80 \%$ of participants agreed or strongly agreed that they were confident that they could find the information they needed when doing independent research. Faculty surveys seemed to support this confidence amongst students and $76.92 \%$ of faculty surveyed agreed that students could find the information they needed when doing independent research.

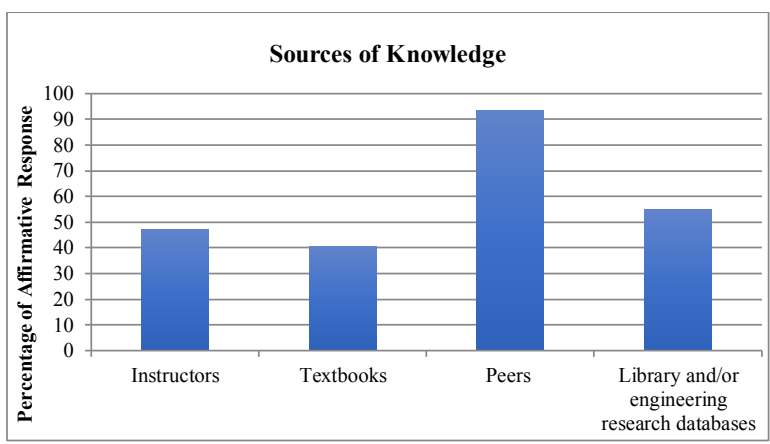

Figure 4: SSE student sources of knowledge

When interviewed, the faculty participants noted that formal classes on research skills that could assist students in locating information beyond class were not provided. However, professors did provide opportunities for students to learn about how to use library resources or utilize specific databases. If additional assistance was needed for researching skills, the students were supported by professors individually through informal discussions. Rather than providing formalized instruction on them, SSE professors promoted the development of research skills by setting expectations of how individual research skills are necessary for success in their courses.

Where students were locating information also showed a high level of independent and self-directed learning. $71.43 \%$ of students surveyed agreed or strongly agreed that they were constantly searching for new sources of knowledge, however where they were searching for this 
knowledge showed some interesting results. $47.03 \%$ stated that they agreed or strongly agreed that they used their instructors as sources of knowledge. Only $54.77 \%$ agree or strongly agreed that they utilized the library and/or engineering research databases for class assignments and projects and only $40.48 \%$ agreed or strongly agreed that they used textbooks as their main source for knowledge throughout their program. What we found to be the most interesting data collected for this characteristic was that a very high percentage of students surveyed $(92.5 \%)$ agreed or strongly agreed that they often utilized the knowledge of their peers for assistance.

Though it is surprising that SSE students utilize their peers for sources of knowledge at such a high rate compared to other sources of knowledge, from a lifelong learning perspective this was an excellent result. Lifelong learning is about learners accessing and locating different sources of knowledge from different contexts. Again, faculty might have something to do with this high use of peers. When asked to respond to the statement, "I encourage students to utilize the knowledge of their peers to assist them with projects and assignments" $84.61 \%$ of faculty participants agreed or strongly agreed. Faculty encouragement for peer-based learning was reinforced by their responses in interviews. Faculty encouraged student consultation of peers for tacit knowledge in design courses as well as peer-to-peer study groups. Professors that taught senior capstone design courses facilitated channels of communication between groups to encourage transmission of knowledge learned outside of the formal curriculum.

SSE scored very highly for this characteristic which was an excellent result for fostering lifelong learning in students. Students expressed a variety of places where they located information as well as a variety of communities where they asked for help. Faculty also felt strongly that they encouraged their students to locate information in different places, by adopting different styles of learning activities and encouraged their students to utilize various learning sources, including their peers.

\subsection{Adaptable learning strategies}

Adaptable learning strategies that enable students to contextualize their learning to changing environments are an important consideration in the CEAB's definition of lifelong learning. It is important to foster this characteristic in students if institutions wish them to become confident and adept learners throughout life, able to meet the challenges of a rapidly changing world. Adaptable learning strategies is an element that is hard to measure in course descriptions or learning objectives, but our research clearly showed some evidence that SSE courses are encouraging students to adapt their learning strategies throughout their program.

One way to assess if students are adapting their learning strategies in their courses is to see how they attempt to

CEEA18; Paper 017

University of British Columbia; June 3-6, 2018 learn from other contexts beyond the formal classroom or from more informal situations inside classroom settings. Figure 5 shows the variety of places students found themselves learning throughout their courses [11]. In student surveys, SSE students showed strong numbers in this area. $86.11 \%$ of students agreed or strongly agreed that they collaborated with peers inside their classes. $69.45 \%$ agreed or strongly agreed to the statement "I problemsolved outside of my class by asking colleagues and family members" while $63.89 \%$ agreed or strongly agreed that they learned outside the classroom from more informal or social spaces. SSE alumni surveys indicated that student ability to learn from informal spaces translated into workplaces in ways that assisted individuals to learn in and from various contexts.

Some students adapted to learning challenges by using resources beyond the classroom. One respondent credits peers and reflection for helping them achieve success, "After my first year of studies, my grades were not that great. I needed to reflect on how I was learning and try to come up with strategies to help understand the material. In second year, I was able to utilize peers to help me achieve success." Another student said they used "textbooks, Google and YouTube videos for explanations" to help them solve problems that come up in class. This trend towards learning from resources beyond the formal curriculum observed in students were paralleled in the alumni data.

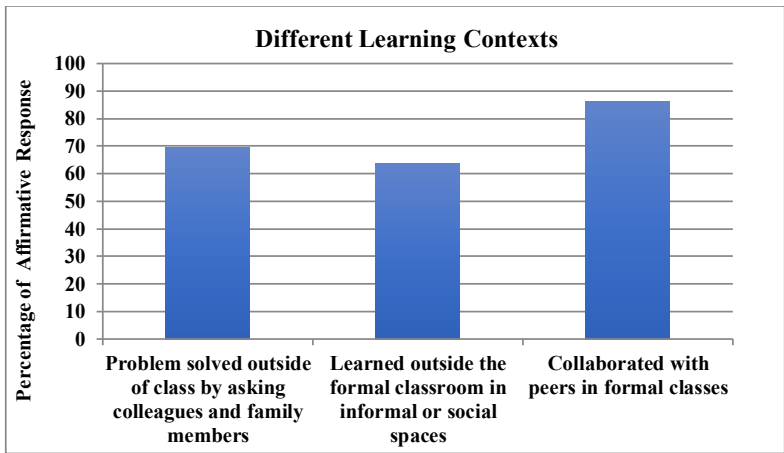

Figure 5: Student survey responses to how they learn from other contexts

SSE faculty were strong proponents of encouraging students to adapt their learning strategies beyond the classroom with $71.43 \%$ agreed or strongly agreed that they were given opportunities to learn outside of the classroom. These responses pointed to evidence that SSE students were comfortable and found it beneficial to view more informal and social spaces as educative, a characteristic that helps develop lifelong learners. Despite the fact that course material does not explicitly state that students should be able to adapt their learning strategies, it would appear that SSE students are confident in feeling that they can adapt their learning strategies to help them succeed in their program. 
When interviewed, faculty shed light on the ways that informal learning is encouraged that was not clear in the course binder material. This insight shows that to really gain a true understanding of a program's intentions one needs to see the program from multiple perspectives or holistically. Professors across programs all expressed the ways in which they encouraged intrinsic motivation, selfdirected exploration of topics beyond the formal curriculum, and the value of peer-based learning through informal discussions. These discussions were also used to clearly illustrate to students the necessity for lifelong learning in becoming a holistic engineer. The SSE study abroad program offered explicit opportunities for students to learn from experts and contexts beyond academia such as unfamiliar cultures. Many faculty interview participants noted the ways in which senior design courses easily lent themselves to opportunities for students to develop adaptable learning strategies even without the travel and culture shock offered by study abroad programs. SSE professors discussed how the individualized nature of learning to design a self-designated project with little supervision and immediate connections between their work and industry often gave motivation and numerous occasions for students to self-adjust their learning strategies.

While some professors utilized the nature of group design courses to promote adaptable learning strategies, some others had to be more intentional. One professor mentioned how his introduction of "design thinking" to his students could be framed to encourage them to adjust their thoughts and assumptions regarding engineering design. Another member of the SSE faculty took note of how openended labs wherein students are given a problem to solve without formulaic lab instructions promoted self-adjusted learning. In interviews, SSE faculty agreed that one of the goals of their pedagogy was to assist students in developing confidence. The interviews revealed that SSEprofessors are aware of the need for confidence to coincide with technical knowledge and critical thinking so that students can adapt and apply their ways of learning to various contexts with conviction. SSE undergraduates were confident in adapting their learning strategies to different contexts.

It would appear that this student confidence is a direct result of faculty helping them develop the skills and ability to adapt those skills to different contexts. SSE alumni felt $70 \%$ confident that SSE programs and courses gave them the confidence to learn new things after graduation. The intentionality with this characteristic of lifelong learning is strongly reflected in both student survey results, alumni surveys results and faculty interviews.

\section{CONCLUSIONS}

From this assessment SSE clearly fosters lifelong learning through specific instructor practices and pedagogical methods. Student and Alumni surveys show high degrees of confidence and ability as a result of their time in SSE. The faculty are clearly engaged with facets of lifelong learning and are intentionally designing elements of courses to reflect goal setting, application of knowledge and skills, self-direction and evaluation, locating information, and adaptable learning strategies. The following are specific insights that came from our report through a recommendations section [11].

Design Courses with Intentionality: Designing courses with intentions of fostering the specific skills of goal setting, application of knowledge and skills, self-direction and evaluation, locating information, and adaptable learning strategies would provide more consistency in promoting lifelong learning to SSE students. The design of courses with lifelong learning attributes in mind would assist in developing a culture of lifelong learning; an essential component of effectively fostering holistic engineers.

Promote Peer-to-Peer Learning to Relieve Resource Limitations: Throughout the interviews, resources challenges such as class time, seminar sizes, and instructor/TA time repeatedly came up as major hindrances to effective pedagogy. One way to combat resource limitations is already being utilized in capstone design courses wherein instructors facilitate channels of communication and transparency between project groups to encourage the transmission of knowledge learned outside of the formal curriculum. In the same respect, more classes should be engineered so that students rely less on instructors as their sole source of knowledge and make use of large seminar sizes as a large wealth of knowledge.

Validate and Facilitate Informal Learning: Though some SSE faculty clearly acknowledge learning can take place beyond the formal classroom setting, developing lifelong attributes could be furthered with more explicit communication to students that learning can happen in other environments. One-on-one interactions with professors and other experts in the field should be engineered into formal class times or assignments and students should be given greater opportunities to learn beyond the classroom, whether that be through field studies, field trips, or study abroad. Efforts to include formal and informal discussions regarding the value of informal learning should be included in all courses that seek to promote lifelong learning. Faculty and facets of intentionally designed courses should reinforce that students have not become experts in their field through

CEEA18; Paper 017

University of British Columbia; June 3-6, 2018 
their degree, rather that they have been equipped with the tools to continue learning throughout their lives.

Provide Greater Lifelong Learning Resources to Instructors: While many of the SSE instructors effectively incorporated lifelong learning pedagogical techniques into their teaching, it was clear that there still remained some confusion amongst faculty. Throughout the faculty interviews, the instructors made note of lifelong learning or effective pedagogy workshops and seminars that they had attended. There is a clear desire to further foster lifelong learning attributes, but instructors seem to be left to find their own way regarding best practices. More accessible or even mandatory teaching seminars that go over effective ways of communicating expectations of lifelong learning as well as teaching students how to selfappraise, goal set, and become more metacognitive would provide support for instructors seeking to implement lifelong learning pedagogy.

Best Practice Guidelines for Assessment and Cross Faculty Communication: It was made clear through the faculty interviews that there existed a discrepancy amongst professors regarding the most effective means to assess for application of knowledge and skills. These discrepancies

\section{Acknowledgements}

The authors would like to acknowledge the University of Calgary's Schulich School of Engineering for their financial support and to the Department of Communication, Media and Film for their logistical support in the completing of this project.

\section{References}

[1] Gert Biesta, "What's the point of lifelong learning if lifelong learning has no point? On the democratic deficit of policies for lifelong learning," European Educational Research Journal, vol. 5, no. 3-4, pp.169-180, 2006.

[2] Sanneke Bolhuis, "Towards active and self-directed learning. Preparing for lifelong learning, with reference to Dutch secondary education," Learning and Instruction, vol.13, pp. 327-347, 2003.

[3] Canadian Engineering Accreditation Board, 2015 A Guide to Outcomes Based Education / Bureau canadien d'agrément des programmes de génie: Normes et procédures d'agrément. Ottawa, ON: Engineers Canada / Ingénieurs Canada, 2015.

$35 \mathrm{pp}$. Available from

https://engineerscanada.ca/.../draft_program_visitor_guide_v1. 25.pdf

CEEA18; Paper 017

University of British Columbia; June 3-6, 2018 point toward a need for best practice guidelines regarding assessment geared for lifelong learning. The confusion found amongst only some of the faculty may also indicate that there could be benefits to communication between professors regarding assessment techniques that they have found effective. SSE should facilitate workshops or meetings in which faculty from different programs can cross-pollinate and brainstorm best practices for assessment.

Highlight and Foster Student Confidence: Students and faculty alike valued the confidence fostered through SSE curricula. Faculty made clear that they felt student confidence was essential for lifelong learning to take place. Intentionality in facilitating opportunities for students to lead independent knowledge acquisition and application, showcase their work to faculty and peers, and receive nongrade-based positive incentive for their engagement and adaptability should be better integrated into the program. Low stake competitions, fun, non-graded elements of assignments and classroom engagement activities as well as ways of celebrating student work such as portfolios would not only facilitate the development of student confidence but would also promote students to develop intrinsic motivations to lead.
[4] Edgar Faure, Felipe Herrera, Abdul-Razzak Kaddoura, Henri Lopes, Arthur V. Petrosky, Majid Rahnema, and Frederick Champion Ward, "Learning to be: The world of education today and tomorrow," in UNESCO, Edgar Faure (ed.) (Paris; August 1972), 39 pp., 1972.

[5] John Field, Lifelong Learning and the New Educational Order. London, UK: Trentham Books. 2006 (2nd ed.) 208 pp. \{ISBN 1858563461\}

[6] Andre P. Grace, "Lifelong learning as a chameleonic concept and versatile practice: $\mathrm{Y} 2 \mathrm{~K}$ perspectives and trends," International Journal of Lifelong Education, vol. 23, no. 4, pp. 385-405, 2004.

[7] Paul, J. Hager, (2011). "Concepts and definitions of lifelong learning," In The Oxford Handbook of Lifelong 
Proc. 2018 Canadian Engineering Education Association (CEEA-ACEG18) Conf.

Learning, 1st ed., M. London, Ed. Oxford, UK: Oxford

University Press, 2011, pp. 12-25. \{ISBN 978-0-19-539048-3\}

[8] John R. Kirby, Christopher Knapper, Patrick Lamon, and William, J. Egnatoff, "Development of a scale to measure lifelong learning," International Journal of Lifelong Education, vol. 29, no. 3, pp. 291-302, 2010.

[9] Christopher Knapper, and Arthur, J. Cropley, Lifelong learning in higher education. London, UK:

Psychology Press, 2000 (3rd ed.), 238 pp. \{ISBN 978-

0749427948\}
[10] Alan Parkinson, "Developing the attribute of lifelong learning," In Frontiers in Education Conference, 1999. FIE'99. 29th Annual, (San Juan, Puerto Rico; 10-13, Nov. 1999) 16 pp., 1999

[11] Lisa Stowe and Rachel Huh, Assessment of Lifelong Learning Attributes in the Schulich School of Engineering: A Formal Review. Calgary, AB: University of Calgary, 2017, $36 \mathrm{pp}$.

[12] Lisa Stowe, The Effects of Time and Space on Developing Lifelong Learners in One Short-Term Travel Study Program, Calgary, AB: University of Calgary, 2016.

CEEA18; Paper 017

University of British Columbia; June 3-6, 2018 